IJBPAS, February, Special Issue, 2022, 11(2): 189-194

ISSN: $2277-4998$

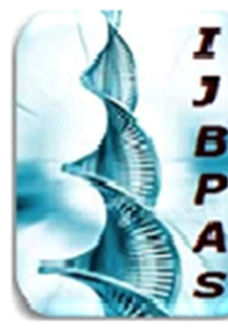

International Journal of Biology, Pharmacy and Allied Sciences (IJBPAS)

'A Bridgs Betusen Caboratory and Qandor'

Www.ijbpas.com

\title{
SURGERY AFTER COVID-19 INFECTION RAISES DEATH RISK- A COHORT STUDY
}

\author{
JOSHI RS ${ }^{1 *}$, BHOSALE $S^{2}$ AND NAGVEKAR $M^{3}$ \\ 1: Junior Resident, Department of Surgery, Krishna Institute of Medical Sciences Deemed \\ To Be University, Karad, Maharashtra (India)
}

2: Professor, Department of Surgery, Krishna Institute of Medical Sciences Deemed To Be

University, Karad, Maharashtra (India)

3: Associate Professor, Department of Surgery, Krishna Institute of Medical Sciences

Deemed To Be University, Karad, Maharashtra (India)

*Corresponding Author: Dr. Rajeev Shrinivas Joshi: E Mail: iamrajeevioshi@gmail.com

Received $15^{\text {th }}$ July 2021; Revised $18^{\text {th }}$ Aug. 2021; Accepted $29^{\text {th }}$ Oct. 2021; Available online $15^{\text {th }}$ Feb. 2022

https://doi.org/10.31032/IJBPAS/2022/11.2.1026

\begin{abstract}
Background: The impact of COVID-19 on postoperative recovery needs to be comprehended to inform clinical decision making during and after the COVID-19 pandemic. This study reports 30-day death risks in patients with perioperative COVID-19 infection Methods: This observational cohort study in Krishna hospital Karad, India included all patients undergoing surgery who had COVID-19 infection confirmed 7 days before or 30 days after surgery. The result measure was 30-day postoperative deaths and was evaluated in all enrolled patients.
\end{abstract}

Findings: This analysis included 110 patients who had surgery between July 1 and September 31, 2020. 30-day mortality was 23.63\% (26 of 110). Men had higher 30 day mortality than women $28.33 \%$ (17 of 60 ) vs $18 \%$ (9 of 50). Patients aged 70 years or older had higher mortality than patients younger than 70 years $33.33 \%$ (18 of 54) vs $14.28 \%$ (8 of 56). Mortality was higher after emergency surgery $25.6 \%$ (21 of 82 ) than elective surgery $20 \%$ (5 of 25$)$.

Interpretation: Threshold level necessary for surgery during the COVID-19 pandemic should be greater than during normal practice, particularly in men aged 70 years and older. 
Thought should be given for postponing routine procedures and encouraging non-operative treatment to postpone or avoid the need for surgery.

\section{INTRODUCTION}

COVID-19 has now reached to most countries, since WHO declared a COVID19 pandemic on March 11, 2020. This pandemic has tested the strength of healthcare systems, including hospitals, which were largely ill-equipped for the level of the pandemic [2]. Patients having surgery are a susceptible cluster at risk of COVID19 exposure in hospital $[\mathbf{3}, \mathbf{4}]$. Proof of the safety of conducting surgery in COVID-19 exposed hospitals is urgently needed. Before the COVID-19 pandemic, highquality, multinational observational studies ascertained overall baseline rates of 30 day mortality (up to 3\%) after surgery [5-7]. With ideas such as the UK's National Emergency Laparotomy Audit (NELA), mortality was decreasing even in high-risk clusters [8]. Regulations have been issued for the management of surgical patients during the COVID-19 pandemic [9], but they are based completely on expert opinion. The effect of COVID-19 on mortality needs to be established in order to allow surgeons and patients to make evidence-based decisions during this pandemic. This study reports the clinical outcomes of patients who underwent surgery with perioperative COVID-19 infection.
Aim

To study 30-day death risks in patients with perioperative COVID-19 infection

Methods

\section{Study design}

An observational cohort study was done in patients with COVID-19 infection who had surgery at Krishna hospital Karad, India. We gathered only routine, anonymised data with no change to clinical care pathways

\section{Participants}

All patients who underwent surgery had COVID-19 diagnosed within 7 days before or 30 days after surgery. Any procedure done by a surgeon in an operating theatre under general, regional, or local anaesthesia was considered as Surgery. Patients undergoing surgery for any indication were qualified, including trauma, benign disease, cancer. There was no age limit.

\section{Procedures}

Laboratory testing for COVID-19 infection was based on viral RNA detection by quantitative RT-PCR. Sampling, including nasal swabs and oropharyngeal swabs and analysis was done according to hospital protocols.

Operative variables consist urgency (elective or emergency surgery), primary procedure completed. Emergency surgery 
was described as procedures classified by the National Confidential Enquiry into Patient Outcome and Death as immediate, urgent, or expedited. ${ }^{1}$ Grade of surgery was categorised on the foundation of the Bupa schedule of procedures as either minor (minor or intermediate) or major (major or complex major). Before finalising the dataset for evaluation, data completeness and that all eligible patients had been entered into the database was checked.

\section{Outcomes}

The outcome was 30-day mortality, with the day of surgery described as day.

Table 1: Baseline and demographic characteristics

\begin{tabular}{|c|c|c|c|}
\hline & \multicolumn{2}{|c|}{30 day mortality } & \\
\hline & NO - $(n=84)$ & YES - $(n=26)$ & \\
\hline \multicolumn{4}{|l|}{ AGE } \\
\hline$<70$ years & 48 & 8 & \\
\hline$>70$ years & 36 & 18 & \\
\hline \multicolumn{4}{|l|}{ SEX } \\
\hline Male & 43 & 17 & \\
\hline Female & 41 & 9 & \\
\hline \multicolumn{4}{|l|}{ Co morbidities } \\
\hline Smoker & 8 & 2 & \\
\hline Asthma & 5 & 2 & \\
\hline Cancer & 14 & 43 & \\
\hline CKD & 10 & 5 & \\
\hline CHF & 5 & 3 & \\
\hline Diabetes & 20 & 7 & \\
\hline Hypertension & 39 & 16 & \\
\hline Myocardial infarction & 7 & 4 & \\
\hline
\end{tabular}

Table 2: Preoperative assessment

\begin{tabular}{|c|c|c|c|}
\hline \multirow{2}{*}{} & \multicolumn{2}{|c|}{ 30 day mortality } & \\
\cline { 2 - 4 } & NO- $(\mathrm{n}=\mathbf{8 4})$ & YES $(\mathbf{n}=\mathbf{2 6})$ & \\
\hline SARS- CoV 2 diagnosis & \multicolumn{2}{|c|}{26} & \\
\hline Lab confirmed & $84 \quad$ No- alive Yes - expired \\
\hline
\end{tabular}

Table 3: Operative details

\begin{tabular}{|c|c|c|c|}
\hline & \multicolumn{2}{|c|}{30 day mortality } & \\
\hline & NO- $(n=84)$ & YES $(n=26)$ & \\
\hline \multicolumn{4}{|c|}{ Urgency of surgery } \\
\hline Elective & 23 & 5 & \\
\hline Emergency & 61 & 21 & \\
\hline \multicolumn{4}{|c|}{ Surgical Diagnosis } \\
\hline Benign case & 49 & 13 & \\
\hline Cancer & 19 & 7 & \\
\hline Trauma & 16 & 6 & \\
\hline \multicolumn{4}{|c|}{ Grade of surgery } \\
\hline Minor & 22 & 4 & \\
\hline Major & 62 & 22 & \\
\hline
\end{tabular}

\begin{tabular}{|c|c|} 
Table 4: Statistical analysis \\
\begin{tabular}{|c|c|}
\hline AGE & Mortality rate, n/N (\%) \\
\hline$<70$ years & $\mathbf{8 / 5 6 ( 1 4 . 2 8 \% )}$ \\
\hline$>70$ years & $\mathbf{1 8 / 5 4 ( 3 3 . 3 3 \% )}$ \\
\hline SEX & $\mathbf{9 / 5 0 ( 1 8 \% )}$ \\
\hline Female & $\mathbf{1 7 / 6 0 ( 2 8 . 3 3 \% )}$ \\
\hline Male & \\
\hline & \\
\hline Comorbidites & \\
\hline
\end{tabular}
\end{tabular}




\begin{tabular}{|c|c|}
\hline NONE & $1 / 12(8.33 \%)$ \\
\hline One or more & $26 / 98(26.5 \%)$ \\
\hline Urgency & $5 / 25(20 \%)$ \\
\hline Elective & $21 / 82(25.6 \%)$ \\
\hline Emergency & \\
\hline & $4 / 26(15.38 \%)$ \\
\hline Minor & $22 / 86(25.58 \%)$ \\
\hline Major & \\
\hline Surgical Diagnosis & $13 / 62(20.9 \%)$ \\
\hline Benign & $7 / 26(26.92 \%)$ \\
\hline Cancer & $6 / 22(27.27 \%)$ \\
\hline Trauma & \\
\hline n;number of patients, N:total number of patients in that category
\end{tabular}

\section{Statistical Analysis}

The study was carried out corresponding to STROBE guidelines for observational studies [11]. Continuous data were checked for distribution, mean and 95\% CI with normally distributed data and differences between groups were tested with unpaired $t$ test. Analysis was done using Strata version 15.2 for Mac.

\section{RESULTS}

At the time of analysis, 30-day follow-up had been reached for 110 patients who had surgery between July 1 and September 31, 2020. $60(54.54 \%)$ of 110 patients were men and 50(45.45\%) were women, 56 $(50.90 \%)$ were younger than 70 years, and $54(49 \cdot 09 \%)$ were aged 70 years or older,. COVID-19 diagnosis was confirmed authenticated by laboratory testing in 110 $(100 \%)$ patients,. Emergency surgery was carried out in $82(74.54 \%)$ of 110 patients and elective surgery in 28(25.45\%);), Indications for surgery were benign disease in $62(56.36 \%)$, cancer in $26(23.63 \%)$, and trauma in $22(20 \%) .26 \quad(23.63 \%)$ procedures were classified as minor and 84 $(76.36 \%)$ as major. Procedures included neurosurgery, head and neck, vascular, orthopaedic, gastrointestinal and general surgery, cardiothoracic, hepatobiliary, urological and other surgeries. 30-day mortality was $23.63 \%$ (26 of 110 ). Men had higher 30 day mortality than women $28.33 \%$ (17 of 60$)$ vs $18 \%$ (9 of 50 ). Patients aged 70 years or older had higher death rates than patients younger than 70 years $33.33 \%$ (18 of 54 ) vs $14.28 \%$ (8 of 56). Mortality was higher after emergency surgery $25.6 \%$ (21 of 82 ) than elective surgery $20 \%$ ( 5 of 25$)$.

\section{DISCUSSION}

This study identified that patients with perioperative COVID-19 infection are associated with high mortality. The increased risks linked with COVID-19 infection should be matched against the risks of postponing surgery in individual patients; this study recognised men, those with comorbidities, people aged 70 years or older those having cancer surgery, and 
those needing emergency or major surgery as being most susceptible to unfavourable outcomes. Threshold level necessary for surgery during the COVID-19 pandemic should be greater than during normal practice. Men aged 70 years and over who have emergency or major elective surgery are at predominantly high risk of death, although minor elective surgery is also linked with more-than-usual mortality. During COVID-19 outbreaks, Thought should be given for postponing routine procedures and encouraging non-operative treatment to postpone or avoid the need for surgery.

\section{Acknowledgement}

I am thankful to Dr. Nimesh Srivastava, my co-resident, for his constant support and help in making this study possible.

\section{REFERENCES}

[1] Martin IC, Who operates when? II: the National Confidential Enquiry into perioperative deaths 2003 .

[2] Horton R, Offline: COVID-19 and the NHS - "a national scandal". The Lancet, 395(10229), 2020, 1022.

[3] Besnier E, Tuech JJ, Schwarz L, We asked the experts: Covid-19 outbreak: is there still a place for scheduled surgery? "Reflection from pathophysiological data". World journal of surgery, 44(6), $2020,1695-8$.
[4] Huang C, Wang Y, Li X, Ren L, Zhao J, $\mathrm{Hu} \mathrm{Y}$, et al., Clinical features of patients infected with 2019 novel coronavirus in Wuhan, China, The lancet, 395(10223), 2020, 497-506.

[5] Kirmeier E, Eriksson LI, Lewald H, Fagerlund MJ, Hoeft A, Hollmann M, et al., Post-anaesthesia pulmonary complications after use of muscle relaxants (POPULAR): a multicentre, prospective observational study, The Lancet Respiratory Medicine, 7(2), 2019, $129-40$.

[6] Neto AS, da Costa LG, Hemmes SN, Canet J, Hedenstierna G, Jaber $\mathrm{S}$, et al., The LAS VEGAS risk score for prediction of postoperative pulmonary complications: An observational study, European journal of anaesthesiology, 35(9), 2018, 691 .

[7] Tu RH, Lin JX, Li P, Xie JW, Wang $\mathrm{JB}, \mathrm{Lu} \mathrm{J}$, et al., Prognostic significance of postoperative pneumonia after curative resection for patients with gastric cancer, Cancer medicine, 6(12), 2017, 2757-65.

[8] NELA Project Team, First patient report of the National Emergency Laparotomy Audit. 
[9] Coccolini F, Perrone G, Chiarugi M, Di Marzo F, Ansaloni L, Scandroglio I, et al., Surgery in COVID-19 patients: operational directives, World Journal of Emergency Surgery, 15(1), 2020, 17.

[10] Tao KX, Zhang BX, Zhang P, Zhu P, Wang GB, Chen XP, Recommendations for general surgery clinical practice in novel coronavirus pneumonia situation, Zhonghua wai ke za zhi [Chinese Journal of Surgery], 58, 2020, E001.

[11] Von Elm E, Altman DG, Egger M, Pocock SJ, Gøtzsche PC, Vandenbroucke JP, The Strengthening the Reporting of Observational Studies in Epidemiology (STROBE) statement: guidelines for reporting observational studies, Bulletin of the World Health Organization, 85, 2007, 867-72. 